\section{The injury of serotonin on intestinal epithelium cell renewal of weaned diarrhoea mice}

\author{
Y. Dong, ' C. Yang,' Z. Wang, ' Z. Qin, ${ }^{2}$ \\ J. Cao, ${ }^{1}$ Y. Chen ${ }^{1}$ \\ 'Laboratory of Veterinary Anatomy, \\ College of Animal Medicine, China \\ Agricultural University, Beijing \\ ${ }^{2}$ Institute of Poultry, Shandong Academy \\ of Agricultural Sciences, Jinan, China
}

\section{Abstract}

Diarrhoea is a common cause of death in children and weaned animals. Recent research has found that serotonin (5-HT) in the gastrointestinal tract plays an important role in regulating growth and the maintenance of mucosa, which protect against diarrhoea. To determine the influence of 5 -HT on intestinal epithelium cell renewal under weaned stress diarrhoea, a weaned-stress diarrhoea mouse model was established with senna infusion $(15 \mathrm{~mL} / \mathrm{Kg})$ via intragastric administration and stress restraint (SR). Mice with an increase in 5-HT were induced by intraperitoneal injection with citalopram hydrobromide $(\mathrm{CH}, 10 \mathrm{mg} / \mathrm{Kg})$. The results demonstrated that compared with the control animals, diarrhoea appeared in weaned stress mice and the 5-HT content in the small intestine was significantly increased $(\mathrm{P}<0.05)$. Further, the caspase- 3 cells and cells undergoing apoptosis in the small intestine were significantly increased, but the $\mathrm{VH}$ (villus height), V/C (villus height /crypt depth), and PCNA-positive rate significantly decreased. Compared with the control animals, $\mathrm{CH}$ increased the intestinal 5-HT content, caspase- 3 cells and cells undergoing apoptosis but decreased the $\mathrm{VH}$ and V/C. Compared with both control and weaned stress animals, weaned stress animals that were pre-treated with $\mathrm{CH}$ showed higher 5 -HT concentrations, positive caspase- 3 cells and cells undergoing apoptosis but lower $\mathrm{VH}, \mathrm{V} / \mathrm{C}$ and PCNA-positive rate. In vitro, a low concentration of 5-HT inhibit, IEC-6 cell line apoptosis but a higher concentration of 5 -HT promoted it. Therefore, weaned stress diarrhoea mice were accompanied by a 5 -HT increase in the small intestine and vice versa, and the increase in 5 - $\mathrm{HT}$ induced by $\mathrm{CH}$ caused diarrhoea. In brief, 5-HT and diarrhoea slowed the intestinal epithelium cell renewal and injured the abortion function and mucosal barrier by decreasing $\mathrm{VH}, \mathrm{V} / \mathrm{C}$ and proliferation and increasing epithelium cell apoptosis.

\section{Introduction}

Diarrhoea causes 1 to 2.5 billion illnesses and 1.5 to 2.5 million deaths per year in children under the age of 5 in developing countries. ${ }^{1,2}$ Post-weaning is one of the most stressful developmental periods and induces psychological stress, which is closely associated with gastrointestinal distress, including intestinal structure, endosomes and lysosomes in enterocytes. ${ }^{3-5}$ Marked changes occur in gut structure and function after weaning, such as villous atrophy and crypt hyperplasia, which are closely associated with digestion and the absorption ability of the small intestine. ${ }^{6}$ The mechanism of stress diarrhoea is closely associated with the neuroendocrine system. Serotonin (5-HT), a neuroendocrine transmitter, is nearly $95 \%$ in the gastrointestinal tract. Furthermore, 5-HT is co-localised with many gut hormones (cholecystokinin and secretin) in the enteroendocrine cells (EC) of different gut regions. ${ }^{7}$ The effect of 5-HT on diarrhoea has been broadly explored. This neurotransmitter acts as a potent paracrine secretagogue in all parts of the small intestine and colon and in all studied species, including humans. ${ }^{8}$ However, 5-HT can not cause diarrhoea in healthy animals and humans because the actions of 5-HT are terminated by uptake via the serotonin reuptake transporter (SERT) into epithelial cells. ${ }^{9}$ In SERT -/- mice, the watery diarrhoea is probably attributable to the potentiation of serotonergic signalling. ${ }^{10}$ Differential defecation responses to stress may be associated with colon 5 -HT concentration, which may in turn reflect the individual sensitivity to 5 -HT of $\mathrm{C} 57 \mathrm{BL} / 6$ mice, but not $\mathrm{BALB} / \mathrm{c}$ mice; thus, the relation between 5 -HT and stress diarrhoea depends on the strain. ${ }^{11}$

Further, 5-HT is an important enteric mucosal signalling molecule that regulates intestinal secretion, microcirculation, ${ }^{2}$ and peristaltic reflexes. ${ }^{13}$ A report confirmed that intestinal epithelium is under serotonergic regulation and further suggested that neuronal 5 -HT provides a drive that increases the villus size by enhancing crypt epithelial cell proliferation. EC cell-derived 5-HT probably opposes this effect and induces epithelium apoptosis; thus, both VH (villus height) and CD (crypt depth) were increased over WT in TPH1K0 mice. ${ }^{14}$ Moreover, 5-HT mediates intestinal secretion via the activation of at least the epithelial 5-HT2, neuronal 5-HT3, and 5-HT4 receptors in the submucosal plexus, including a reflex arc. Furthermore, Gershon ${ }^{15}$ found that enteric 5-HT is a polyfunctional sig-
Correspondence: Prof. Yaoxing Chen, Laboratory of Veterinary Anatomy, College of Animal Medicine, China Agricultural University, Haidian, Beijing 100193, China.

Tel. +86.10.62733778 - Fax: +86.10.62733199.

E-mail: yxchen@cau.edu.cn

Key words: 5-HT; weaned stress mice; intestinal epithelium cell; proliferation; apoptosis.

Contributions: YD, study design; data analysis, manuscript drafting; CY, data acquisition and analysis; ZW, manuscript drafting and final approval; ZQ, critical manuscript revision for important intellectual content; JC, study design revision; YC, important contributions to the manuscript, final approval of the version to be published. All authors read and approved the final version of the manuscript.

Conflict of interest: the authors disclose that there is no conflict of financial interest that influenced this work.

Acknowledgments: this work was supported by National High-tech Research and Development Projects (863) (No. 2013AA102306), and National Natural Science Foundation of China (No. 31272483, 30671514, 31372332).

Received for publication: 24 May 2016.

Accepted for publication: 6 December 2016.

This work is licensed under a Creative Commons Attribution-NonCommercial 4.0 International License (CC BY-NC 4.0).

(C) Copyright $Y$. Dong et al., 2016

Licensee PAGEPress, Italy

European Journal of Histochemistry 2016; 60:2689 doi:10.4081/ejh.2016.2689

nalling molecule that acts, in both developing and mature animals, as a neurotransmitter paracrine factor, endocrine hormone and growth factor; they also noted that the effect of 5 -HT regulation on diarrhoeal disease is still unclear, although much evidence has been found. To explore the mechanism of 5-HT's role on weaned stress diarrhoeal disease, 21-daysto-weaned mice were used as experimental animals and treated with citalopram hydrobromide (CH), which is a highly selective serotonin reuptake inhibitor that increases the amount of 5-HT synthesis. Further, mucosal proliferation and apoptosis were examined in the study.

\section{Materials and Methods}

\section{Animal treatments}

All animals were kept in stainless steel cages and acclimated for 2 days at constant 
temperature and humidity, and a 12-h lightdark cycle was maintained. The mice were fed with standard chow and given free access to water. Then, a model for experimental stress diarrhoea in weaned mice was established. Eighty, 21-day-old, ICR male mice (weaned, 12-14 g, Vital River Laboratory Animal Technology Co. Ltd., Beijing, China) were divided into four groups, with twenty mice per group: i) control mice, treated with vehicle (normal saline) intraperitoneally; ii) stressrestraint group (SR), treated with a folium senna infusion (concentration of $0.4 \mathrm{~kg} / \mathrm{L}$ ) via intragastric administration at a dose of 15 $\mathrm{mL} / \mathrm{kg}$ body weight, followed by rest for 20 min. The mice were then stress-restricted such that the hind leg activities were controlled by bandages for $4 \mathrm{~h}$ every day, but the forelimbs were not limited. The mice were permitted free-feeding water. Folium senna is a strong stimulant laxative that stimulates peristalsis via the intestinal mucosa and nerves, which mimics food stimulation to the gastrointestinal tract. Restraint stress is a traditional model of psychological stress that is similar to separation from the mother; ${ }^{11,16}$ iii) $\mathrm{CH}$ control group, mice were treated with a dose of $\mathrm{CH}(10 \mathrm{mg} / \mathrm{kg} \mathrm{BW}$, dissolved in 0.1 mL $0.9 \%$ saline) injected intraperitoneally to observe whether a 5 -HT increase induced by CH caused diarrhoea in the mice; iv) Stressrestraint diarrhoea, pre-treated with citalopram mice $(\mathrm{SR}+\mathrm{CH})$ : these mice were pretreated with a dose of $\mathrm{CH}(10 \mathrm{mg} / \mathrm{kg} \mathrm{BW}$, dissolved in $0.1 \mathrm{~mL} 0.9 \%$ saline) injected intraperitoneally. After $4 \mathrm{~h}$, mice were stressrestrained such that that the activity of the hind legs was controlled by bandages for $4 \mathrm{~h}$ every day, but the forelimbs were not limited; the mice were permitted free-feeding water. All mice were treated for at least $5 \mathrm{~d}$; based on these groups, mice were then anaesthetized using $2 \%$ pentobarbital $(4 \mathrm{~mL} / \mathrm{kg}$ ), and the intestinal segments were harvested. All animal procedures were approved by the China Agricultural University Institutional Animal Care and Use Committee (XK20110915).

\section{Tissue preparation}

The intestinal segments were fixed in $4 \%$ paraformaldehyde and then embedded in paraffin for histological and immunohistochemical analyses. Portions of unfixed intestinal segments were rapidly homogenized, and clarified lysates were obtained by centrifugation (1000 x g for $20 \mathrm{~min}$ ). The tissue extracts were stored at $-80^{\circ} \mathrm{C}$ for 5 -HT analysis by ELISA analysis.

\section{Enzyme-linked immunosorbent assay}

The protein concentrations of the tissue lysates were determined using a bicin- choninic acid (BCA) (mg/mL) prior to ELISA analysis. The 5-HT levels in plasma and intestinal tissue were measured using a biotinlabelling double-antibody sandwich enzymelinked immunosorbent assay (DZE21316, Beijing Limbo Terry Technology Development Co., Ltd, Beijing, China). All tests were performed according to the manufacturers' instructions. The 5-HT detection ranged from 10 to $3000 \mathrm{ng} / \mathrm{L}$, and the final concentrations were presented as $\mathrm{ng} / \mathrm{mL}$ in plasma and as $\mathrm{ng} / \mathrm{g}$ protein in intestine tissue.

\section{Histological and immunohisto- chemical study}

For the histological studies, $4 \mu \mathrm{m}$ thick sections of samples fixed with $4 \%$ paraformaldehyde and embedded in paraffin wax were stained with haematoxylin and eosin (HE). Measurements of the villus heights and crypt depths were performed on HE sections by light microscopy. The villus height and crypt depth were measured in the 45 highest and well-oriented villi, and deepest crypts using the Image Pro Plus 4 analysis software (Media Cybernetics, Baltimore, MD, USA). For immunohistochemical analysis, primary mouse anti-human PCNA antibody (1:1000, AV03018, Sigma-Aldrich, St. Louis, MO, USA) was used and Caspase-3 cleaved polyclonal antibodies (1:200, C8487, Sigma-Aldrich) were incubated with sections overnight at $4^{\circ} \mathrm{C}$, respectively. Goat anti-rabbit IgG, biotinconjugated antibody (1:400, CW0107, CWBioTech, Beijing, China) were incubated with sections for $2 \mathrm{~h}$ at $37^{\circ} \mathrm{C}$. Avidin-biotinperoxidase (1:400, ZSGB-BIO, Beijing, China), diaminobenzidine (DAB) and $\mathrm{H}_{2} \mathrm{O}_{2}$ were used for staining and imaging. The PCNA-positive cell percentage of the total number of crypt epithelial cells was counted for each intestinal crypt. The number of caspase- 3 positive cells was counted from top to half of the intestinal villus. Three animals were chosen from each group, and nine discrete slices were randomly selected from each animal, five rules and neat intestinal crypt and villus were observed for each slice. One hundred thirty-five intestinal crypts (for PCNA) and villi (for caspase-3) were counted in total for each group.

\section{TUNEL assay for apoptosis in intestine}

The terminal deoxynucleotidyl transferasemediated deoxyuridine triphosphate nick-end labelling (TUNEL) assay (4810-30-K, Roche, Beijing Zhongshan Gold Bridge Co., Ltd., Beijing, China) was performed according to the manufacturer's instructions. Sections

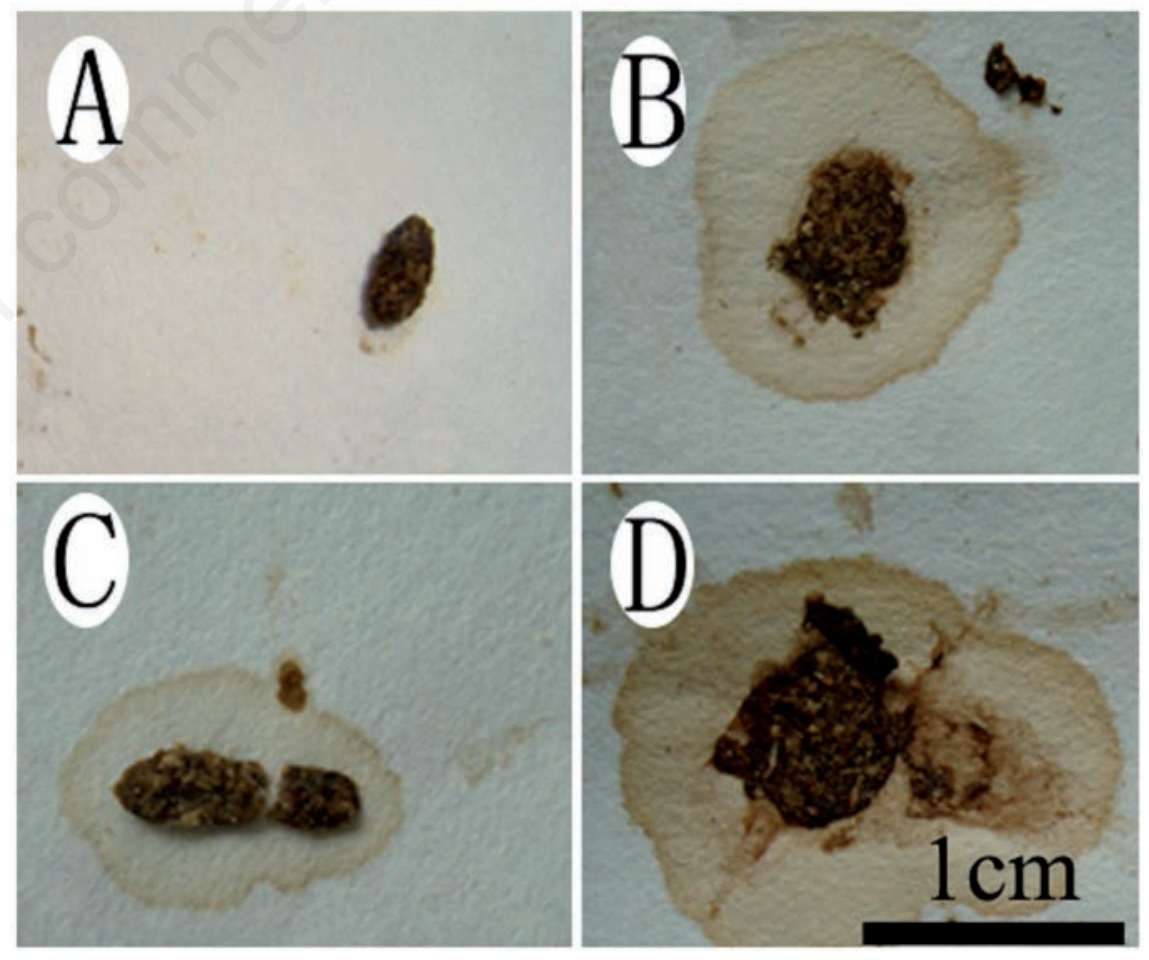

Figure 1. Changes in excrement characters in different treatment mice. Normal faeces were hard and granular (A), but the faeces were softer and a small amount of water appeared in both the stress-restrained mice (B) and $\mathrm{CH}$ control (C) groups. Furthermore, serous watery stool was shown in the stress $+\mathrm{CH}$ group (D). Scale bar: $1 \mathrm{~cm}$. 
were incubated in TUNEL reaction solution for $60 \mathrm{~min}$ at $37^{\circ} \mathrm{C}$, after being washed 3 times by $\mathrm{PBS}$, and were then incubated in POD for 30 min at $37^{\circ} \mathrm{C}$, after being washed 3 times by PBS. Then, 50-100 $\mu \mathrm{L}$ DAB was used for staining and imaging in $15-25^{\circ} \mathrm{C}$ for $10 \mathrm{~min}$; haematoxylin redyeing. The positive cell data were counted from top to half of the intestinal villus. In total, one hundred thirty-five intestinal villi were counted for each group.

\section{Flow cytometry detection for cell apoptosis assay}

Enough IEC-6 cells were cultivated for experiments. Cells were seeded in $60 \mathrm{~mm}$ petri dishes at the same density of $5 \times 10^{3}-10^{4}$ cells/well after digestion and centrifugation, and cultured in DMEM for $12 \mathrm{~h}$. Abandoning the liquid, cells were cultured with complete medium containing $0,10,25,50,100,500$ and $1000 \mu \mathrm{M}$ of 5 -HT, respectively, for $48 \mathrm{~h}$. Then, $2 \mathrm{~mL}$ of $0.1 \mathrm{M}$ D-Hank's solution was added to the petri dish for $3 \mathrm{~min}$, and then the D-Hank's was abandoned. The cells were digested with $500 \mu \mathrm{L}$ 0.05\% Trypsin solution at $37^{\circ} \mathrm{C}$ for $10-15 \mathrm{~min}$. After the cells fell off, 1 $\mathrm{mL}$ of complete medium containing 10\% foetal bovine serum was added to stop digestion, followed by transfer into a $15-\mathrm{mL}$ centrifuge tube and centrifugation for $5 \mathrm{~min}$ at $1000 \mathrm{~g}$; thereafter, the suspension was abandoned. Cells were washed with $1 \mathrm{~mL}$ of $0.1 \mathrm{M}$ D-Hank's for 2 times. Then, $100 \mu \mathrm{L}$ of $1 \times$ Bingbuffer was added to sediment, which was next transferred into flow cytometry tubes. Then, the cells were stained with $5 \mu \mathrm{L}$ of Annexin V-FITC and $5 \mu \mathrm{L}$ of propidium iodide (PI) in the dark for $15 \mathrm{~min}$. Next, 400 $\mu \mathrm{L}$ of $1 \times$ Binding Buffer was added and analysed using flow cytometry. Each sample was assayed three times.

\section{Statistical analysis}

Data were expressed as the mean \pm SD. To analyse the results, diarrhoea scores were analysed by applying a non-parametric test, and $\mathrm{k}$ independent samples and other data were analysed by a parametric test, One-Way ANOVA, in SPSS 11.5. Differences were considered significant $(\mathrm{P}<0.05) . \mathrm{P} \approx 0.000$ was represented as $\mathrm{P}<0.001$.

\section{Results}

\section{Diarrhoea in mice with different treatments}

Control animals did not have diarrhoea (Figure 1A), and their faeces were hard and granular. However, the faeces were softer, and a small amount of water was observed in both the SR and $\mathrm{CH}$ control group mice.
Furthermore, serous watery stool in the SR + $\mathrm{CH}$ group (Figure 1D) was observed; thus, compared to control animals, treatment with CH significantly changed stool patterns. The 100\% SR mice and CH group exhibited diarrhoea. According to previously reported criteria, ${ }^{17,18}$ the diarrhoea scores of mice were visually assessed each day by independent evaluators, with the score ranging from 1 to 5 (1, normal faeces, which were dry and hard, and showed granular shapes; 2 , moist faeces, which had normal granular appearance; 3 , mild diarrhoea, which showed paste shapes; 4, severe diarrhoea, which showed paste shapes and had circular water stains; 5, watery diarrhoea, which had almost no faeces, except for water). The diarrhoea score in the different treatment groups was statistically analysed by applying a nonparametric test, in $\mathrm{k}$ independent samples, as seen in Figure 2. Compared with control, the diarrhoea scores of mice with SR diarrhoea and SR + $\mathrm{CH}$ animals were higher, at 209.09\% ( $\mathrm{P}=0.002)$ and $259 \%(\mathrm{P}=0.000)$, respectively. There was no difference between $\mathrm{SR}+\mathrm{CH}$ animals and the $\mathrm{CH}$ group. Thus, the method in this study could cause diarrhoea, and $\mathrm{CH}$ could aggravate the diarrhoeal symptoms.

\section{5-HT changes in plasma and intes- tine of different treatment mice}

To observe the relevance between 5 -HT and diarrhoea, 5 -HT concentration was tested by ELISA in different treatment mice. Compared to the control group, the 5-HT level of plasma increased significantly by $33.42 \%(\mathrm{P}=0.001)$ and $64.77 \%(\mathrm{P}=0.000)$ in $\mathrm{SR}$ and $\mathrm{CH}$ group mice, respectively (Figure $3 \mathrm{~A}$ ). The 5 -HT level in plasma in $\mathrm{SR}+\mathrm{CH}$ mice increased by $46.77 \%(\mathrm{P}=0.000)$ compared to $\mathrm{SR}$ mice and by $18.85 \%(\mathrm{P}=0.000)$ compared to the $\mathrm{CH}$ control group. The 5-HT change tendency in intestine was similar to that observed in plasma (Figure 3B). In the control mice, the 5-HT concentration of intestine increased from duodenum to ileum. Compared with control mice, when mice were treated with stress, the 5 -HT concentration increased by $33.20 \%$ $(\mathrm{P}=0.002), 17.32 \% \quad(\mathrm{P}=0.001)$, and $18.01 \%$ $(\mathrm{P}=0.001)$ in duodenum, jejunum and ileum, respectively. Similar to the changes in SR mice, compared with control mice, the 5-HT concentration of $\mathrm{CH}$ mice increased by $39.25 \% \quad(\mathrm{P}=0.001), 9.06 \% \quad(\mathrm{P}=0.112)$, and $17.16 \%(\mathrm{P}=0.001)$ from duodenum to ileum, respectively. In the $\mathrm{SR}+\mathrm{CH}$ mice, the concentration of 5 -HT increased significantly by 24.30\%-37.27\% compared with SR mice $(\mathrm{P}=0.000)$ and by $25.21-35.15 \%$ compared with $\mathrm{CH}$ mice $(\mathrm{P}=0.000)$. These data show that stress diarrhoea is accompanied by an increase of 5-HT concentration and clarify the promotion effect of $\mathrm{CH}$ on 5 -HT synthesis.

\section{Changes of intestine morphology in treated mice}

The microscopic morphology was observed with HE staining. The pathological changes were obvious in the ileum. Hyperaemia appeared at the apex of the intestinal villus,

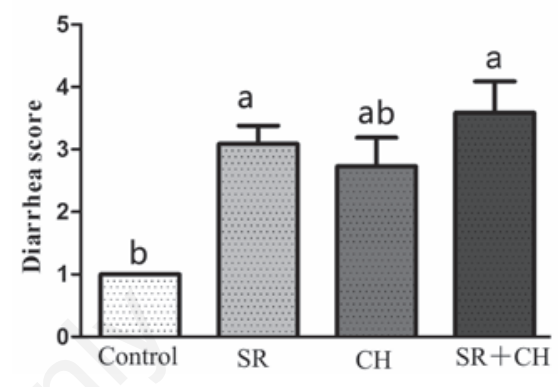

Figure 2. The diarrhoea scores of mice were assessed visually, with the score ranging from 1 to 5 . A higher score indicates more severe diarrhoea. Different letters on the bar indicate a significant difference among groups $(P<0.05)$; $S R$, stressrestraint; $\mathrm{CH}$, citalopram; $\mathrm{SR}+\mathrm{CH}$, stressrestraint + citalopram.

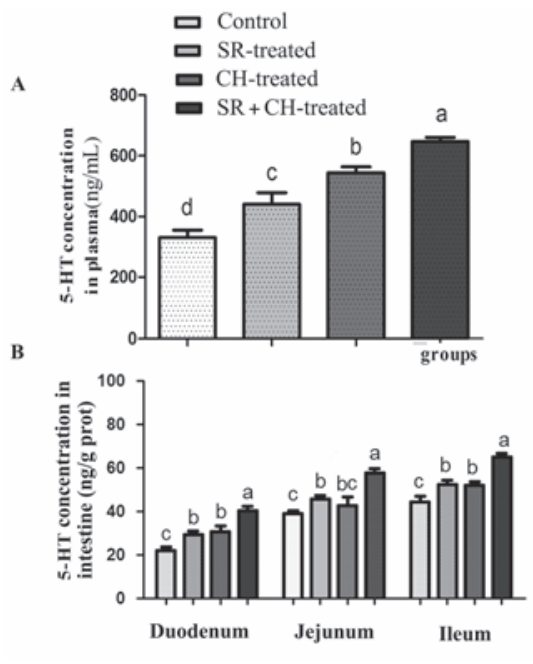

Figure 3. 5-HT concentrations in the plas$\mathrm{ma}$ and intestine of mice by ELISA. Both stress and $\mathrm{CH}$ increased the 5-HT levels, which was highest in plasma in the $\mathrm{SR}+\mathrm{CH}$ group among all four groups (A). The change tendency of 5-HT concentration in intestine (B) was similar to the changes in plasma. Different letters in the same column indicate a significant difference among groups within the same intestine segments $(P<0.05)$; $S R$, stressrestraint; $\mathrm{CH}$, citalopram; $\mathrm{SR}+\mathrm{CH}$, stressrestraint + citalopram. 
the intestinal epithelium cell had fallen away and exposed of lamina propria, and the villus had shortened in $\mathrm{CH}$ and SR mice (Figure 4). Furthermore, the villus height $(\mathrm{VH})$ and crypt depth (CD), which indicated intestinal villus's absorptive functions, were measured. The $\mathrm{VH}$ was significantly lower, reaching $14.73 \%$ in duodenum $(\mathrm{P}=0.000), 6.89 \%$ in jejunum $(\mathrm{P}=0.000)$ and $22.69 \%$ in ileum $(\mathrm{P}=0.000)$ in $\mathrm{SR}$ mice compared to the control
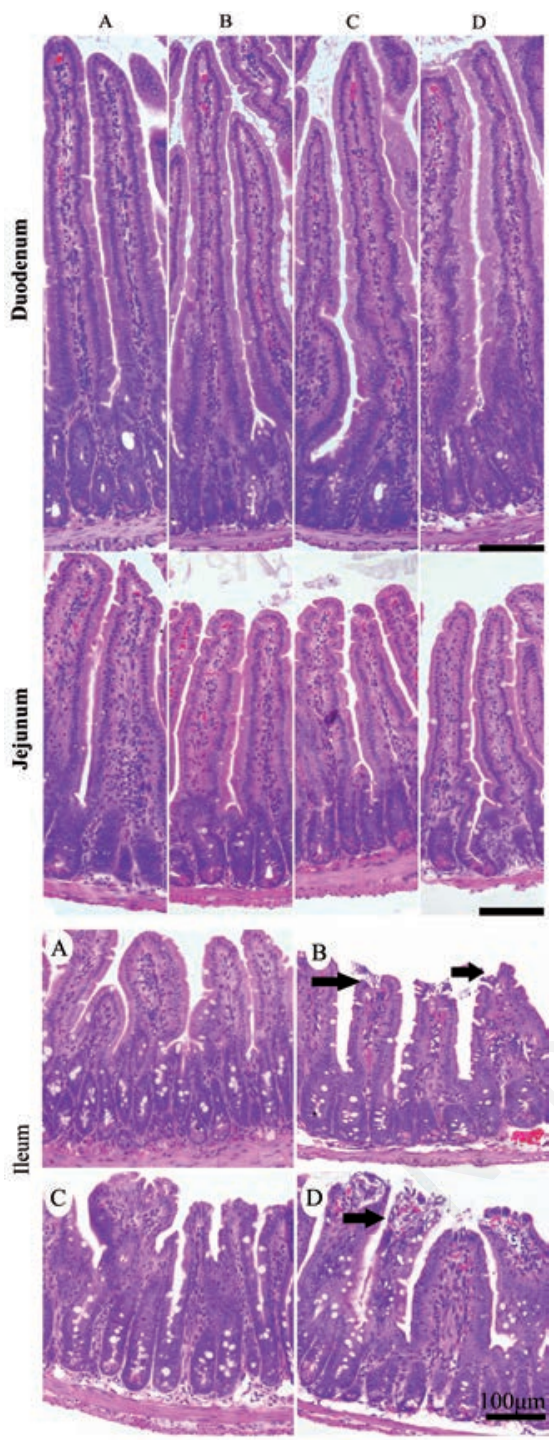

Figure 4. The changes of intestine morphology in different treatment mice (HE staining). The pathological changes were obvious in ileum: hyperaemia appeared at the apex of the intestinal villus, the intestinal epithelium cells had fallen away and exposed the lamina propria (black arrows), and the villus had shortened. The control group showed normal mucous membrane structure, and basic integrity in ileum. A) Control group. B) Stressrestraint group. $\mathrm{C}) \mathrm{CH}$-treated group. $\mathrm{D}$ ) stress-restraint $+\mathrm{CH}$ group. animals. Similar to the SR group, compared to control animals, CH-treated mice showed the same changes; a decrease of $8.71 \%$ in duodenum $(\mathrm{P}=0.000), \quad 14.55 \%$ in jejunum $(\mathrm{P}=0.000)$ and $18.91 \%$ in ileum $(\mathrm{P}=0.000)$. Compared to the SR mice, for SR $+\mathrm{CH}$ mice, $\mathrm{VH}$ in jejunum was significantly decreased by $11.18 \%(\mathrm{P}=0.028)$ but increased by $7.70 \%$ in ileum $(\mathrm{P}=0.003)$. The $\mathrm{CD}$ in $\mathrm{SR}$ mice was significantly greater, at $14.09 \%$ in duodenum $(\mathrm{P}=0.000), 4.95 \%$ in jejunum $(\mathrm{P}=0.041)$ and $11.53 \%$ in ileum $(\mathrm{P}=0.000)$ compared to the control group. The changes in $\mathrm{CH}$ control mice were similar to the SR group; compared to the SR group, CD was significantly increased by $4.86 \%$ in duodenum $(\mathrm{P}=0.012)$ in the $\mathrm{SR}+\mathrm{CH}$ mice. The ratio of $\mathrm{VH}$ and $\mathrm{CD}$ (V/C) was analysed. As shown in Figure 5, compared to control mice, SR mice demonstrated a significantly shorter V/C in duodenum, 25.10\% ( $\mathrm{P}=0.000)$, jejunum, $4.75 \%$ $(\mathrm{P}=0.003)$ and ileum, $46.19 \%(\mathrm{P}=0.000)$. Similarly, the changes in $\mathrm{CH}$ mice significantly decreased, and among the four groups, SR $+\mathrm{CH}$ mice exhibited the maximum decrease. Thus, stress diarrhoea could decrease VH and increase $\mathrm{CD}$, with the ratio of $\mathrm{V} / \mathrm{C}$ rapidly falling off. $\mathrm{CH}$ aggravated the pathological changes.

Changes of proliferation in epithelium cells in treated mice

To explore the mechanism of the $\mathrm{VH}$ decrease and CD increase, the intestinal epithelial cell proliferation was detected by PCNA-positive immunity reaction cells using immunohistochemistry staining. The reaction positive cells appeared brown in colour and were mostly located in the base of intestinal villi and crypts (Figure 6). Compared to control animals, treatment with stress diarrhoea decreased significantly, by $4.48 \%$ in duodenum $(\mathrm{P}=0.000)$ of the intestinal PCNApositive rate, $8.67 \%$ in jejunum $(\mathrm{P}=0.000)$ and $7.61 \%$ in ileum $(\mathrm{P}=0.000)$. Compared to control animals and similar to SR animals, $\mathrm{CH}$ mice demonstrated a significant decrease in the PCNA-positive rate, with $3.87 \%$ in duodenum $(\mathrm{P}=0.000), 6.19 \%$ in jejunum $(\mathrm{P}=0.000)$ and $3.38 \%$ in ileum $(\mathrm{P}=0.000)$. Compared to $\mathrm{SR}$ animals, $\mathrm{SR}+\mathrm{CH}$ animals experienced a significantly decreased PCNApositive rate, of $5.22 \%$ in duodenum $(\mathrm{P}=0.000), 3.39 \%$ in jejunum $(\mathrm{P}=0.000)$ and $3.86 \%$ in ileum $(\mathrm{P}=0.000)$. The results showed that both stress diarrhoea and $\mathrm{CH}$ caused a decrease of PCNA expression in mice (Figure 7).
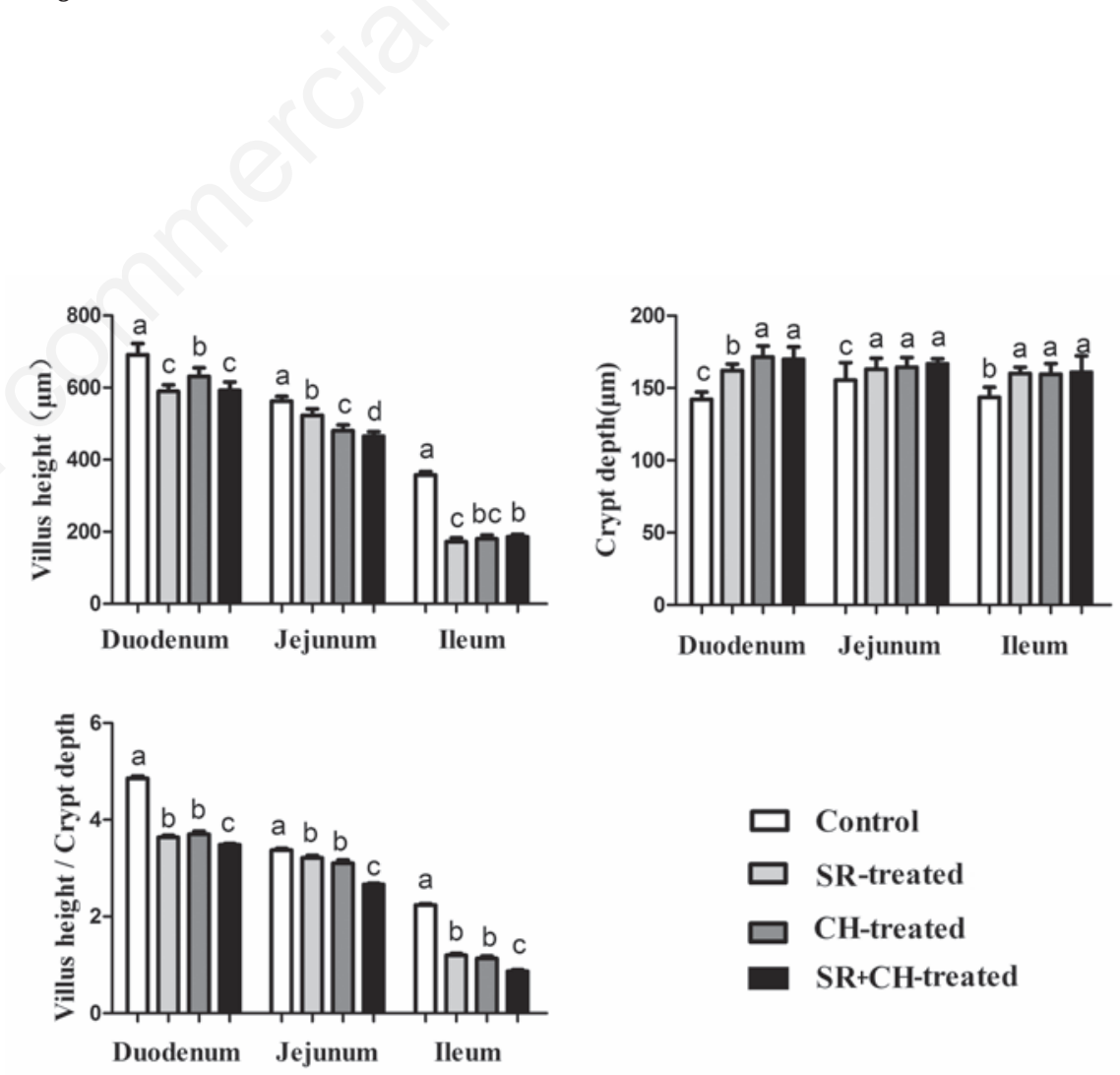

Figure 5. The changes of $\mathrm{VH}, \mathrm{CD}$ and $\mathrm{V} / \mathrm{C}$ in intestines of different treatment mice. The villus height/crypt depth of SR + CH-treated mice decreased the most, among the four groups. Different letters in the same column indicate a significant difference among groups within the same intestine segments $(\mathrm{P}<0.05)$. SR, stress-restraint; $\mathrm{CH}$, citalopram; SR+CH, stress-restraint + citalopram. 


\section{TUNEL analysis in intestine of treated mice}

The TUNEL procedure was used to identify the location and quantity of apoptotic cells in control and other groups. Apoptotic epithelial cells were found predominantly in the tip extrusion zone of villus (Figure 8). The number of cells undergoing apoptosis of $1 / 2$ villus was counted, as shown in Figure 9, and was significantly increased by $126.21 \%$ in duodenum $\quad(\mathrm{P}=0.000), \quad 54.31 \%$ in jejunum $(\mathrm{P}=0.000), 86.05 \%$ in ileum $(\mathrm{P}=0.000)$ of $\mathrm{SR}$ mice compared to the control. Similarly, compared to control animals, the $\mathrm{CH}$-treated group also showed significantly greater increases, except for duodenum. Unsurprisingly, $\mathrm{CH}$ treatment significantly accelerated epithelial apoptosis. Compared to the SR group, epithelial apoptosis in $\mathrm{SR}+\mathrm{CH}$ mice increased significantly by $167.38 \%$ in duodenum $(\mathrm{P}=0.000), 91.93 \%(\mathrm{P}=0.000)$ in jejunum, and $135.14 \%$ in ileum $(\mathrm{P}=0.000)$. Generally, excess 5-HT-induced $\mathrm{CH}$ in intestine accelerated the apoptosis of enterocytes in both normal and stress mice.

\section{Changes of caspase- 3 expression in intestinal epithelial cell of mice}

To verify the apoptotic state of the intestinal epithelial cell, caspase-3 positive immunity reaction positivity was measured by immunohistochemistry staining. As shown in Figure 10 , the reaction cells appeared brown in colour, the caspase-3-positive cells were expressed mainly in epithelium cell nuclei at the top of the villus, and few were located at lamina propria, which was almost similar to that of TUNEL. Compared to control animals, the number of caspase-3-positive cells of mice with stress diarrhoea increased significantly by $288.65 \%$ in duodenum $(\mathrm{P}=0.000), 63.03 \%$ in jejunum $(\mathrm{P}=0.000), 89.08 \%$ in ileum $(\mathrm{P}=0.000)$. Compared with control animals, similar to stress-diarrhoea mice, treatment with $\mathrm{CH}$ significantly increased $186.52 \%$ in duodenum $(\mathrm{P}=0.000), 129.70 \%$ jejunum $(\mathrm{P}=0.000)$ and $64.63 \%$ ileum $(\mathrm{P}=0.000)$. Compared with SR mice, SR + CH mice exhibited the highest increase in duodenum (40.69\%, $\quad \mathrm{P}=0.000)$, jejunum $\quad(76.52 \%$, $\mathrm{P}=0.000)$, ileum $(66.74 \%, \mathrm{P}=0.000)$ (Figure 11). Thus, stress diarrhoea induced the increase of caspase- 3 positive cells of mice, and $\mathrm{CH}$ caused more caspase- 3 positive expression in stress-diarrhoea mice.

\section{Effect of 5-HT on apoptosis of IEC- 6 cell lines by flow cytometry analysis}

To test the effect of 5-HT on apoptosis of IEC-6 cell lines, we detected apoptosis by flow cytometry analysis of concurrent staining with Annexin V-FITC and PI. The results are shown in Figure 12A; cells in early stage of apoptosis were stained with Annexin V, whereas those in late apoptosis were stained with Annexin V and PI, and the sum of the two percentages is the total percentage of apoptotic cells. The statistical results in Figure $12 \mathrm{~B}$ show that in a specific concentration range $(0-25 \mu \mathrm{M})$, the total percentage of apoptotic cells was reduced as the concentration of 5-HT increased. The rate of apoptosis was the lowest at a concentration of $25 \mu \mathrm{M}$. In contrast, when the 5-HT concentration was greater than $25 \mu \mathrm{M}$, the rate of apoptotic cell accumulation increased. The percentage of apoptosis was the highest when it reached $1000 \mu \mathrm{M}$. Therefore, a low concentration of 5HT could inhibit IEC-6 cell apoptosis; in contrast, a high concentration promoted the rate of total cell apoptosis.

\section{Discussion}

Diarrhoea in newborns and pre-weaned piglets, which causes increased mortality, poor growth and additional medical costs, is also one of the most serious threats in the swine industry. It is estimated that $50 \%$ of piglet mortality is due to diarrhoeal deaths. ${ }^{19}$ Thus, weaning is one of the most stressful periods for children and animals. Associated with weaning are marked changes to the histology and biochemistry of the small intestine, such as villous atrophy and crypt hyperplasia, which cause decreased digestive and absorptive capacity and contribute to postweaning diarrhoea. ${ }^{6}$ The mechanism of stress on diarrhoea has been extensively studied but remains unclear.

In mammals, approximately $60-90 \%$ of the total amount of 5-HT in the body is in the gastrointestinal tract and is related to several gastrointestinal dysfunctions such as emesis, motility disorders, diarrhoea, and more recently, irritable bowel syndrome. ${ }^{20}$ All infants, but no adult mice, experienced diarrhoea following the administration of 5 -HT. ${ }^{21}$ In the study, $100 \%$ of the stress mice and the CH group showed diarrhoea, and the combination of $\mathrm{CH}$ with stress caused the most serious diarrhoea. Further, the 5-HT level in plasma and intestine significantly increased in both stress mice and the $\mathrm{CH}$ group and was especially high in the stress $+\mathrm{CH}$ mice.

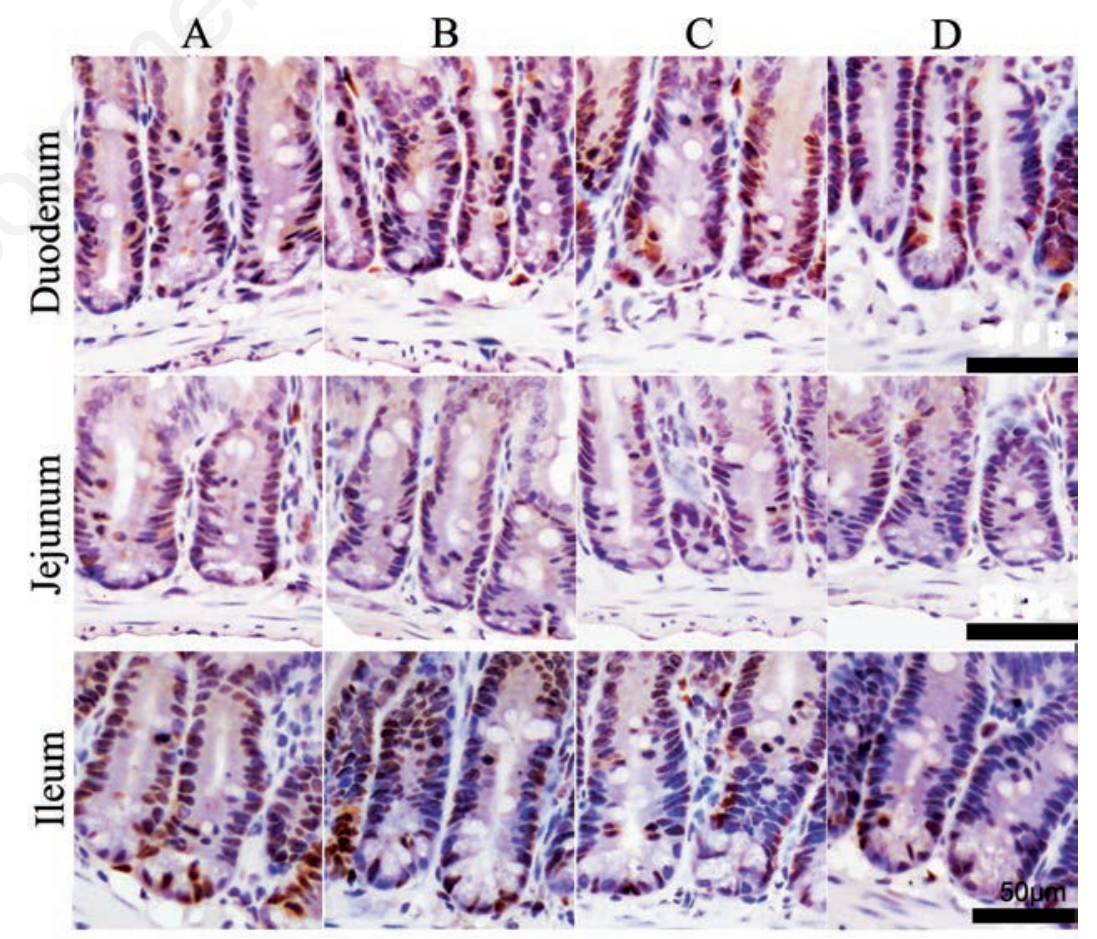

Figure 6. The changes of PCNA-positive immunity reaction cells in intestine of mice (immunohistochemistry staining). The reaction cells appear brown in colour and are mostly located in the base of intestine villi and intestinal crypts. A) Control group. B) Stress-restraint group. C) $\mathrm{CH}$-treated group. D) stress-restraint $+\mathrm{CH}$ group. Scale bars: $50 \mu \mathrm{m}$. 
A similar study found that serotonin of local intestine regulates GI motility and is a key factor in the pathophysiology of stress-associated GI disorders. ${ }^{11}$ Those results indicate that the 5-HT increase could cause diarrhoea and that stress diarrhoea accompanied the 5HT increase. The increased 5-HT content in

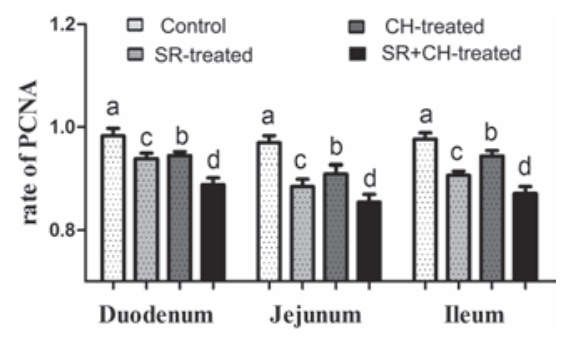

Figure 7. The rate of PCNA-positive immunity reaction cells in intestine of mice. Both stress and $\mathrm{CH}$ decreased the PCNA-positive cell rate, which was lowest in the stress $+\mathrm{CH}$ group, among the four groups. The different letters in the column indicate a significant difference among groups within the same intestine segments $(P<0.05)$. SR, stress-restraint; $\mathrm{CH}$, citalopram; $\mathrm{SR}+\mathrm{CH}$, stress-restraint + citalopram. the brain and intestine had a close relationship with the IBS-D pathogenesis because there were significantly more 5 -HT positive cells in the IBS-D group as well as CGRP and NPY, ${ }^{22,23}$ similar to DSS-colitis, which increased 5 -HT levels by increasing the amount of EC cells and/or the content of 5-HT in the EC cells. ${ }^{24}$ Some studies reported that 5 -HT was increased in plasma in diarrheal IBS-D but exhibited reduced levels in IBSC. ${ }^{25,26}$ However, a decrease in the amount of ileal serotonin cells is associated with the visceral hypersensitivity associated with all IBS subtypes. ${ }^{27}$ Nazir et al. found that the therapeutic mechanism of TGF- $\beta 1$ to GI disorders was increased serotonin transporter (SERT) activity via PI3K and STX3, which regulates the extracellular availability of 5 -HT. ${ }^{28}$ Interestingly, it was verified that the stressdiarrhoea of weaned mice had a direct positive correlation with 5 -HT increase in the study.

Villus height and crypt depth have a close relationship..$^{29-31}$ For instance, a decrease of diarrhoea incidence was accompanied by an increase in villus height of the duodenum and ileum and a decrease in crypt depth of the duodenum in weaned piglets with $\mathrm{ZnO}$-supplemented diets. ${ }^{30}$ Changes in VH and CD are considered key measurements for the assess- ment of gut maturation and nutritional effects. ${ }^{32}$ There are many published papers on the crosstalk of diarrhoea and intestine. of the papers that we retrieved from the PubMed database and Web of Science, $49.69 \%$ were on the relation of diarrhoea and the large intestine, and $26.79 \%$ were on its relation to the small intestine. In this study, the pathological changes were obvious only in ileum. Hyperaemia appeared in the apex of intestinal villus, intestinal epithelium cells had fallen away and exposed the lamina propria, and the villi were shortened in stress and $\mathrm{CH}$ mice. Early weaning induces villous atrophy and crypt hyperplasia in the small intestine, ${ }^{33}$ and a reduction in villous height in the small intestine is associated with reductions in body weight gain after weaning. ${ }^{34}$ Furthermore, there were alterations in electrolytes, and a lengthened crypt compartment in the jejunum in a rat lapatinib-induced diarrhoea model. ${ }^{35}$ Compromising alterations in the villus-crypt structure are common in weaned pigs. Consistent with previous experiments, our current findings showed that intestine $\mathrm{VH}$ was significantly lower and that CD was increased in stress diarrhoea mice compared to control animals. Additionally, 5HT-induced contractions of isolated guinea pig ileum were studied in vitro. ${ }^{36}$ Similar to

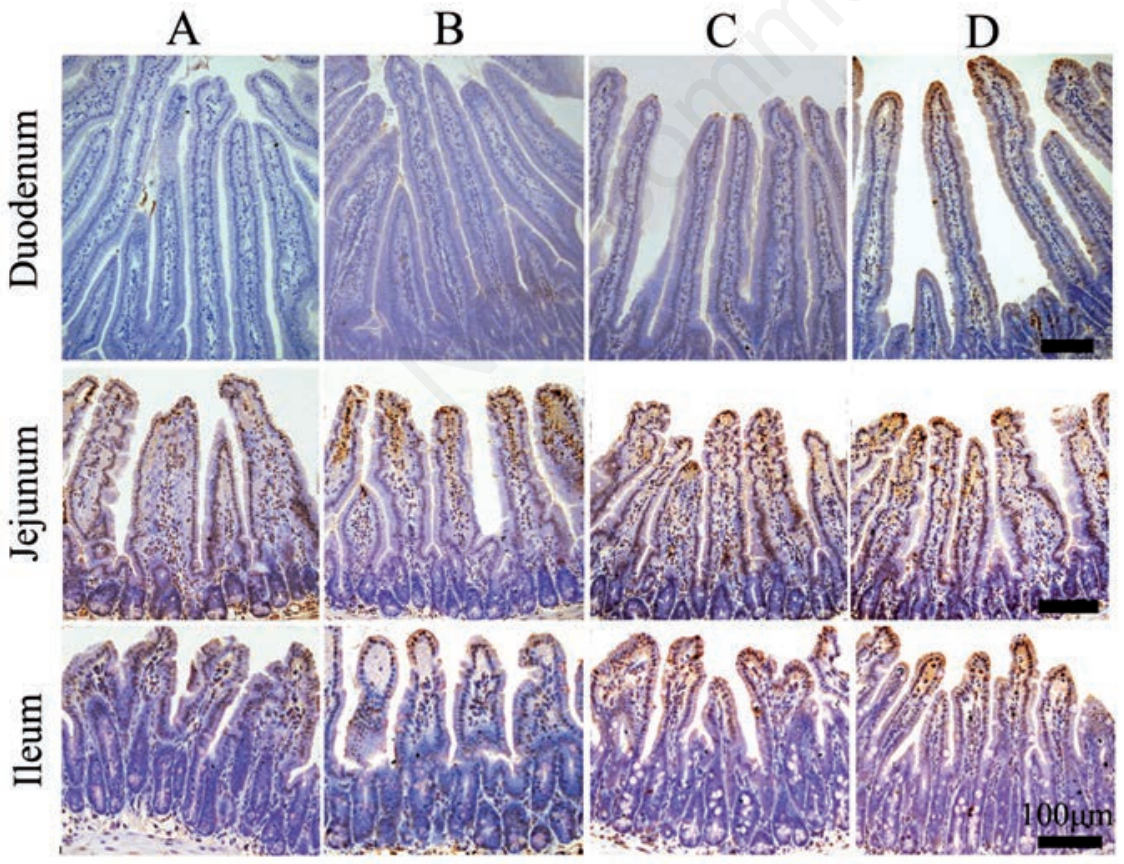

Figure 8. The distribution and morphology of apoptotic cells in intestine of the different treatment mice (TUNEL). The apoptotic cells appear brown in colour, and apoptotic epithelial cells were found predominantly in the tip extrusion zone of villus; A) Control group. B) Stress-restraint group. C) $\mathrm{CH}$-treated group. D) stress-restraint $+\mathrm{CH}$ group. Scale bars: $100 \mu \mathrm{m}$.

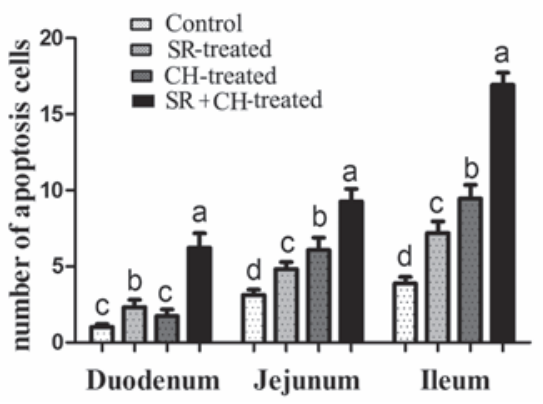

Figure 9. The number of apoptotic cells in intestine of different treatment mice. In stress mice and the $\mathrm{CH}$ group, an increase in apoptotic cells appeared, and the stress $+\mathrm{CH}$ treatment caused the most apoptotic cells in mice. Different letters in the same column indicate a significant difference among groups within the same intestine segments $(\mathrm{P}<0.05)$. SR, stress-restraint; $\mathrm{CH}$, citalopram; $\mathrm{SR}+\mathrm{CH}$, stress-restraint + citalopram. 
stress mice, a 5-HT increase induced by $\mathrm{CH}$ mice showed the same diarrhoea. For $\mathrm{SR}+\mathrm{CH}$ mice, $\mathrm{VH}$ in jejunum was significantly decreased by $11.18 \%$. Compared to control mice, in particular, the ratio of $\mathrm{VH}$ and $\mathrm{CD}$ (V/C) of stress diarrhoea mice was significantly shorter. Similarly, the changes of $\mathrm{CH}$ mice significantly decreased. $\mathrm{SR}+\mathrm{CH}$ mice had the most serious decline among the four groups. Thus, stress diarrhoea could decrease the $\mathrm{VH}$ and increase $\mathrm{CD}$, with the ratio of $\mathrm{V} / \mathrm{C}$ then rapidly falling off. $\mathrm{CH}$ (higher 5 -HT) aggravated the pathological changes. However, Gross reported that growth of the mucosa and proliferation of mucosal cells were significantly greater in SERTKO mice and in mice that were given selective serotonin reuptake inhibitors than in wild-type mice; that even neuronal 5 -HT could promote the growth and turnover of the intestinal mucosal epithelium; and that enteroendocrine-cell-derived 5-HT is an essential component of the gastrointestinal inflammatory response. ${ }^{14,37,38}$ Villous atrophy might be caused by either an increased rate of cell loss or a reduced rate of cell renewal, and increased crypt cell proliferation results in increased villus height, crypt depth and villus hyperplasia. ${ }^{39}$ Furthermore, the proliferation
(PCNA) and apoptosis (TUNEL) of epithelium was observed. The number of PCNA positive cells in both SD and $\mathrm{CH}$ mice was significantly decreased compared to control animals, and that of $\mathrm{CH}+\mathrm{SD}$ animals was significantly decreased compared to SD animals. In contrast, there were significantly more TUNELpositive reaction cells in $\mathrm{SD}$ and $\mathrm{CH}$ mice than in control mice. Indeed, compared to the stress-diarrhoea group, these cells were significantly increased in $\mathrm{CH}+$ stress-diarrhoea mice. From the present results, it was concluded that diarrhoea inhibited proliferation but promoted apoptosis in the intestinal epithelium of weaned mice; even 5 -HT could aggravate the pathological change. Thus, 5HT had a negative effect on stimulating recovery of the intestinal mucosa. However, in SERTKO mice that released 5-HT in excess, the neuronal effect of 5-HT appears to be dominant, leading to larger villi and deeper crypts than in wild type mice; thus, the reason for increased apoptosis with the proliferation of enterocytes might be that the cholinergic neurons that stimulate proliferation also shorten the lifespan of enterocytes, ${ }^{14,40}$ and over $95 \%$ (duodenum) or $75 \%$ (jejunum) of 5 HT enterocyte cells contained cholecystokinin. ${ }^{7}$ Furthermore, in this study, a low concentration of 5 -HT inhibited IEC-6 cell line apoptosis; in contrast, a higher concentration of 5-HT increased the rate of total cell apoptosis in vitro, which was consistent with the in vivo results. The effect of 5-HT on IEC6 cells was similar to the previous report that $1 \mathrm{mM} 5$-HT could significantly increase apoptosis of biopsy-like Burkitt lymphoma cells. ${ }^{41}$ Gastrointestinal neuroendocrine tumour proliferation was autoregulated by 5 -HT by alterations in ERK and JNK signalling. ${ }^{42}$ Additionally, 5-HT has been shown to be involved in pulmonary vascular remodelling in pulmonary arterial hypertension by inducing pulmonary artery smooth muscle cell proliferation and inhibiting apoptosis. ${ }^{43}$ Although the roles of 5 -HT on different cells are diverse, excess 5-HT induced by $\mathrm{CH}$ and stress diarrhoea in intestine accelerated apoptosis and prevented the proliferation of enterocytes in the study. In conclusion, we demonstrated that excessive 5-HT was involved in the intestinal pathological process of stress diarrhoea. In the stress-diarrhoea instance, blocking the reuptake of 5-HT could intensify both the body's stress state and pathological changes in intestinal tract from intestine epithelium proliferation and apoptosis in weaned mice.

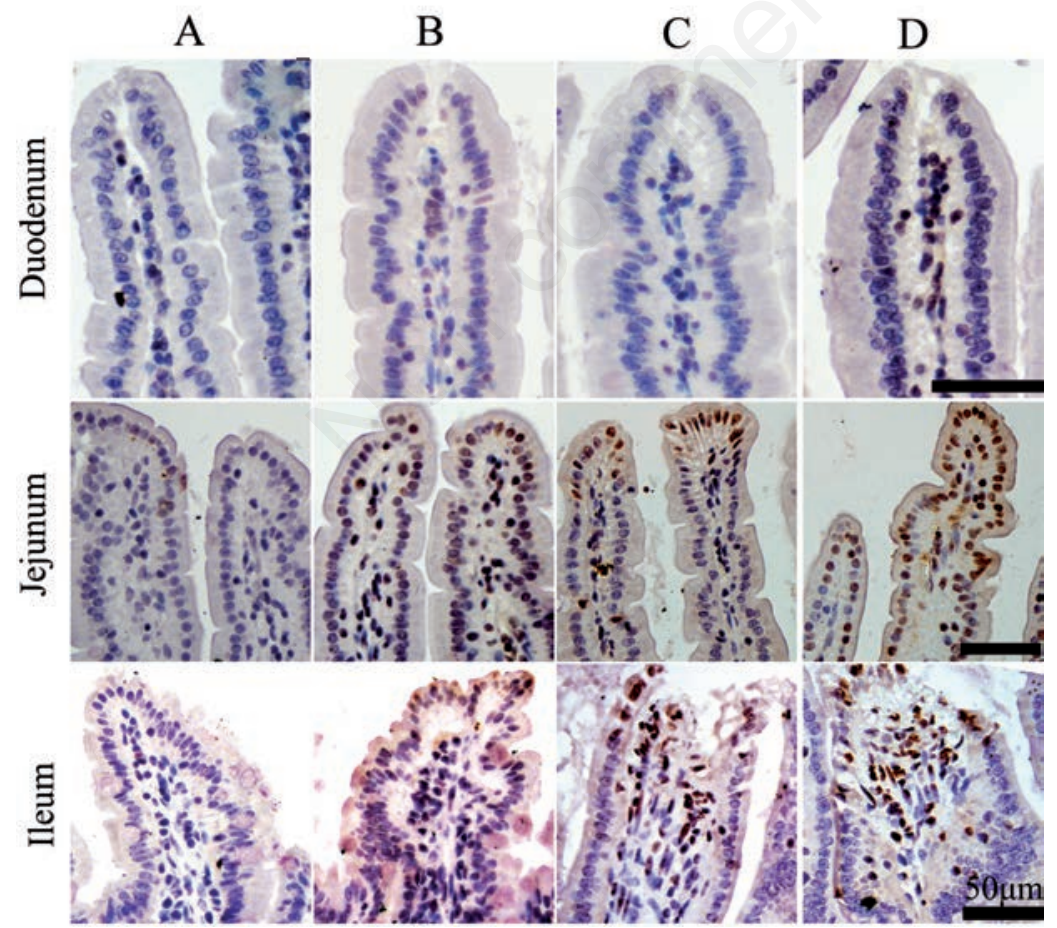

Figure 10. The expression of caspase- 3 positive immunity reaction in intestine of treatment mice (immunohistochemistry staining). The reaction cells appear brown in colour; positive caspase- 3 cells were expressed mainly in nuclei at the top of the villus and were mostly located in epithelium cells, few were located at lamina propria; A) Control group. B) Stress-restraint group. C) $\mathrm{CH}$-treated group. D) stress-restraint $+\mathrm{CH}$ group. Scale bars: $50 \mu \mathrm{m}$.

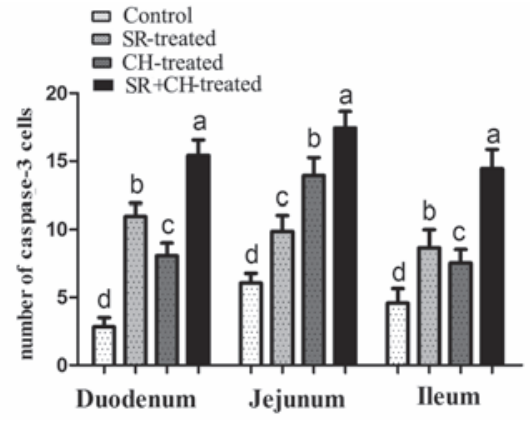

Figure 11. Number of caspase-3 positive immunity reaction cells in intestine of treatment mice. In stress mice and the $\mathrm{CH}$ group, an increase of caspase- 3 positive cells appeared, and stress $+\mathrm{CH}$ treatment caused the most caspase- 3 positive expression in mice. Different letters in the same column indicate a significant difference among groups within the same intestine segments $(P<0.05)$. SR, stress-restraint; $\mathrm{CH}$, citalopram; $\mathrm{SR}+\mathrm{CH}$, stress-restraint + citalopram. 

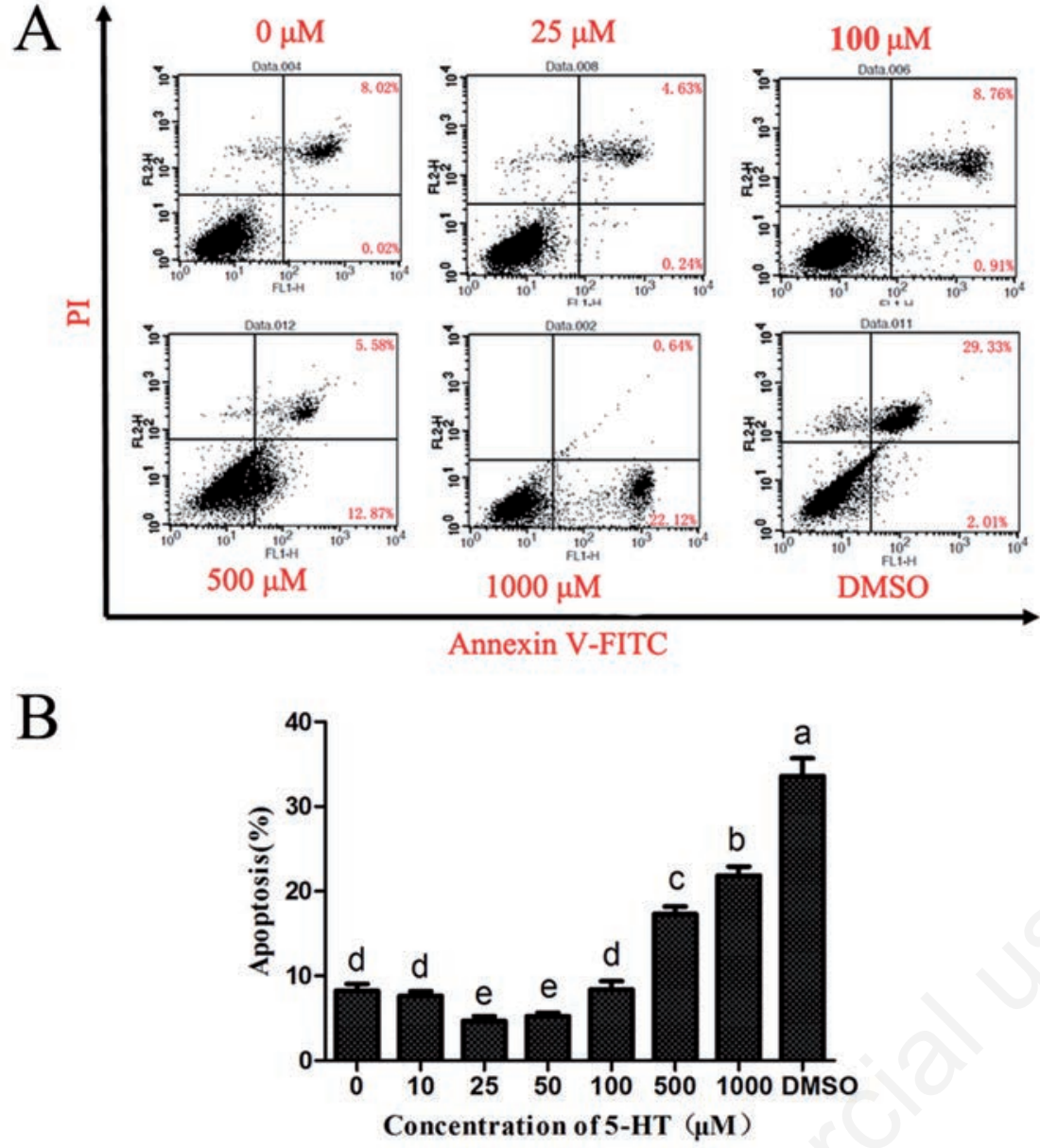

Figure 12. Effect of 5-HT on the apoptosis of IEC-6 cell lines by flow cytometry analysis. A) shows the apoptotic cell distribution, as determined by flow cytometry. B) denotes statistical analysis of the apoptotic cells in the IEC- 6 cells with different concentrations of 5-HT culture. Different letters in the histogram indicate a significant difference among the different treated groups $(P<0.05)$.

\section{References}

1. Wardlaw T, Salama P, Brocklehurst C, Chopra M, Mason E. Diarrhoea: why children are still dying and what can be done. Lancet 2010;375:870-2.

2. Kosek M, Bern C, Guerrant RL. The global burden of diarrhoeal disease, as estimated from studies published between 1992 and 2000. Bull World Health Organ 2003;81: 197-204.

3. Baqui AH, Black RE, Arifeen SE, Hill K, Mitra SN, Al Sabir A. Causes of childhood deaths in Bangladesh: results of a nationwide verbal autopsy study. Bull World Health Organ 1998;76:161-71.

4. Remis NN, Wiwatpanit T, Castiglioni AJ, Flores EN, Cantu JA, Garcia-Anoveros J. Mucolipin co-deficiency causes accelerated endolysosomal vacuolation of enterocytes and failure-to-thrive from birth to weaning. PLoS Genet 2014;10: e1004833.
5. Culpepper T, Christman MC, Nieves C, Specht GJ, Rowe CC, Spaiser SJ, et al. Bifidobacterium bifidum R0071 decreases stress-associated diarrhoea-related symptoms and self-reported stress: a secondary analysis of a randomised trial. Benef Microbes 2016;7:327-36.

6. Pluske JR, Hampson DJ, Williams IH. Factors influencing the structure and function of the small intestine in the weaned pig: a review. Livest Prod Sci1997;51:215-36.

7. Reynaud Y, Fakhry J, Fothergill L, Callaghan B, Ringuet M, Hunne B, et al. The chemical coding of 5-hydroxytryptamine containing enteroendocrine cells in the mouse gastrointestinal tract. Cell Tissue Res 2016;364:489-97.

8. Yu PL, Fujimura M, Okumiya K, Kinoshita M, Hasegawa H, Fujimiya M. Immunohistochemical localization of tryptophan hydroxylase in the human and rat gastrointestinal tracts. J Comp Neurol
1999;411:654-65.

9. Martel F, Monteiro R, Lemos C. Uptake of serotonin at the apical and basolateral membranes of human intestinal epithelial (Caco-2) cells occurs through the neuronal serotonin transporter (SERT). J Pharmacol Exp Ther 2003;306:355-62.

10. Chen JJ, Li ZS, Pan H, Murphy DL, Tamir $\mathrm{H}$, Koepsell H, et al. Maintenance of serotonin in the intestinal mucosa and ganglia of mice that lack the high-affinity serotonin transporter: abnormal intestinal motility and the expression of cation transporters. J Neurosci 2001;21:6348-61.

11. Julio-Pieper M, O’Mahony CM, Clarke G, Bravo JA, Dinan TG, Cryan JF. Chronic stress-induced alterations in mouse colonic 5-HT and defecation responses are strain dependent. Stress 2012;15:218-26.

12. Shcherbakov P, Trubitsyna I, Kirova MV. Serotonin and Acetylcholine associated damage to microcirculation in gastric mucosa and cytokine changes in rats. Gastroenterology 2011;140:S318-S9.

13. Bulbring E, Gershon MD. Serotonin participation in the vagal inhibitory pathway to the stomach. Adv Pharmacol 1968;6:32333 .

14. Gross ER, Gershon MD, Margolis KG, Gertsberg ZV, Cowles RA. Neuronal serotonin regulates growth of the intestinal mucosa in mice. Gastroenterology 2012;143:408-17.e2.

15. Gershon MD. 5-Hydroxytryptamine (serotonin) in the gastrointestinal tract. Curr Opin Endocrinol Diabetes Obes 2013;20:14-21.

16. Servatius RJ, Salameh G, Coyle KM, Paré WP. Restraint stress. In G. Fink (ed.) Encyclopedia of stress. Academic Press; 2007; p. 389-90.

17. Kelly D, Obrien JJ, McCracken KJ. Effect of creep feeding on the incidence, duration and severity of post-weaning diarrhea in pigs. Res Vet Sci 1990;49:223-8.

18. Liu Y, Song M, Che TM, Almeida JAS, Lee JJ, Bravo D, et al. Dietary plant extracts alleviate diarrhea and alter immune responses of weaned pigs experimentally infected with a pathogenic Escherichia coli. J Anim Sci 2013;91:5294-306.

19. Morris RS, Davies PR, Lawton DE. Evolution of diseases in the world's pig industry. Proceedings of the 17th Int. Congr. Pig Vet. Soc. 2002; p. 1-10.

20. Hoyer D, Hannon JP, Martin GR. Molecular, pharmacological and functional diversity of 5-HT receptors. Pharmacol Biochem Behav 2002;71:533-54.

21. Bialowas S, Hagbom M, Nordgren J, Karlsson T, Sharma S, Magnusson KE, et al. Rotavirus and serotonin cross-talk in diarrhoea. PLoS One 2016;11:e159660. 
22. Zou B-c, Dong L, Wang Y, Wang S-h, Cao MB. Expression and role of 5-HT7 receptor in brain and intestine in rats with irritable bowel syndrome. Chin Med J 2007;120: 2069-74.

23. Sun JH, Wu XL, Meng YF, Cheng J, Ning HX, Peng YJ, et al. Electro-acupuncture decreases 5-HT, CGRP and increases NPY in the brain-gut axis in two rat models of diarrhea-predominant irritable bowel syndrome (D-IBS). BMC Complement Altern Med 2015;15:340.

24. Bertrand PP, Barajas-Espinosa A, Neshat $\mathrm{S}$, Bertrand RL, Lomax AE. Analysis of realtime serotonin (5-HT) availability during experimental colitis in mouse. Am J Physiol Gastrointest Liver Physiol 2010;298:G446-55.

25. Zuo XL, Li YQ, Yang XZ, Guo M, Guo YT, Lu $\mathrm{XF}$, et al. Plasma and gastric mucosal 5hydroxytryptamine concentrations following cold water intake in patients with diarrhea-predominant irritable bowel syndrome. J Gastroenterol Hepatol 2007;22:2330-7.

26. Faure C PN, Gauthier C, Brooks EM, Mawe GM. Serotonin signaling is altered in irritable bowel syndrome with diarrhea but not in functional dyspepsia in pediatric age patients. Gastroenterology 2010;139:249-58.

27. El-Salhy M, Gilja OH, Gundersen D, Hatlebakk JG, Hausken T. Endocrine cells in the ileum of patients with irritable bowel syndrome. World J Gastroenterol 2014;20:2383-91.

28. Nazir S, Kumar A, Chatterjee I, Anbazhagan AN, Gujral T, Priyamvada S, et al. Mechanisms of intestinal serotonin transporter (SERT) upregulation by TGFbetal induced non-smad pathways. PLoS
One 2015;10:e0120447.

29. Ritchie JM, Rui HP, Zhou XH, Iida T, Kodoma T, Ito $\mathrm{S}$, et al. inflammation and disintegration of intestinal villi in an experimental model for vibrio parahaemolyticus-induced diarrhea. PLoS Pathog 2012;8:e1002593.

30. Zhu C, Lv H, Chen Z, Wang L, Wu X, Chen $\mathrm{Z}$, et al. Dietary zinc oxide modulates antioxidant capacity, small intestine development, and jejunal gene expression in weaned piglets. Biol Trace Elem Res 2016 [Epub ahead of print].

31. Yang HS, Wu F, Long LN, Li TJ, Xiong X, Liao $P$, et al. Effects of yeast products on the intestinal morphology, barrier function, cytokine expression, and antioxidant system of weaned piglets. J Zhejiang Univ Sci B 2016;17:752-62.

32. Liu P, Pieper R, Tedin L, Martin L, Meyer W, Rieger J, et al. Effect of dietary zinc oxide on jejunal morphological and immunological characteristics in weaned piglets. $\mathrm{J}$ Anim Sci 2014;92:5009-18.

33. Montagne L, Boudry G, Favier C, Le Huerou-Luron I, Lalles J-P, Seve B. Main intestinal markers associated with the changes in gut architecture and function in piglets after weaning. $\mathrm{Br} \mathrm{J}$ Nutr 2007;97:45-57.

34. Tsukahara T, Kishino E, Inoue $\mathrm{R}$, Nakanishi N, Nakayama K, Ito T, et al. Correlation between villous height and the disaccharidase activity in the small intestine of piglets from nursing to growing. Anim Sci J 2013;84:54-9.

35. Bowen JM, Mayo BJ, Plews E, Bateman E, Wignall A, Stringer AM, et al. Determining the mechanisms of lapatinib-induced diarrhoea using a rat model. Cancer Chemother Pharmacol 2014;74:617-27.
36. Smriga M, Torii K. L-Lysine acts like a partial serotonin receptor 4 antagonist and inhibits serotonin-mediated intestinal pathologies and anxiety in rats. Proc Natl Acad Sci USA 2003;100:15370-5.

37. Ghia J-E, Li N, Wang H, Collins M, Deng Y, El-Sharkawy RT, et al. Serotonin has a key role in pathogenesis of experimental colitis. Gastroenterology 2009;1371649-60.

38. Margolis KG, Stevanovic K, Li Z, Yang QM, Oravecz T, Zambrowicz B, et al. Pharmacological reduction of mucosal but not neuronal serotonin opposes inflammation in mouse intestine. Gut 2014;63928-37.

39. Rubin DC, Levin MS. Mechanisms of intestinal adaptation. Best Pract Res Clin Gastroenterol 2016;30:237-48.

40. Harrington AM, Hutson JM, Southwell BR. Cholinergic neurotransmission and muscarinic receptors in the enteric nervous system. Prog Histochem Cytochem 2010;44:173-202.

41. Serafeim A, Grafton G, Chamba A, Gregory $\mathrm{CD}$, Blakely RD, Bowery NG, et al. 5hydroxytryptamine drives apoptosis in biopsylike Burkitt lymphoma cells: reversal by selective serotonin reuptake inhibitors. Blood 2002;99:2545-53.

42. Drozdov I, Kidd M, Gustafsson BI, Svejda B, Joseph R, Pfragner R, et al. Autoregulatory effects of serotonin on proliferation and signaling pathways in lung and small intestine neuroendocrine tumor cell lines. Cancer 2009;115:4934-45.

43. Han X, Chen C, Cheng G, Liang L, Yao X, Yang G, et al. Peroxisome proliferator-activated receptor gamma attenuates serotonin-induced pulmonary artery smooth muscle cell proliferation and apoptosis inhibition involving ERK1/2 pathway. Microvasc Res 2015;100:17-24. 